\title{
DIRECT ESTIMATES FOR GUPTA TYPE GENERAL OPERATORS
}

\author{
EKTA PANDEY* AND R. K. Mishra
}

\begin{abstract}
Gupta in [6] introduced a general family of linear positive operators which produce large number of well known linear positive operators as particular cases. As the family of operators proposed by Gupta provides a unified approach this motivated us to extend the studies, and we establish some convergence estimates of these important operators. We estimate an asymptotic formula and the rate of convergence for these operators for the function having derivatives of bounded variation.
\end{abstract}

Mathematics subject classification (2010): 41A25, 41A30.

Keywords and phrases: Linear positive operator, bounded variation, asymptotic formula, rate of convergence.

\section{REFERENCES}

[1] T. ACAR, L. N. Mishra And V. N. Mishra, Simultaneous approximation for generalized Srivastava-Gupta operators, J. Function Spaces 2014 (2014) 11 pages, Article ID 936308.

[2] R. P. AgARWAL AND V. GuPTA, On q-analogue of a complex summation-integral type operators in compact disks, J, Inequal. Appl. 2012 (1) (2012), 111.

[3] P. N. Agrawal And A. J. Mohammad, Linear combination of a new sequence of linear positive operators, Revista de la U.M.A 42 (2) (2001), 57-65.

[4] N. Deo, M. A. Noor And M. A. Siddiqui, On approximation by a class of new Bernstein type operators, Appl. Math. Comput. 201 (1-2) (2008), 604-612.

[5] V. Gupta, Rate of approximation by a new sequence of linear positive operators, Comput. Math. Appl. 45 (12) (2003), 1895-1904.

[6] V. Gupta, A large family of linear positive Operators, Rend. Circ. Mat. Palermo, II. Ser (2019), https://doi.org/10.1007/s12215-019-00430-3.

[7] N. K. Govil, V. Gupta And D. Soybaş, Certain new classes of Durrmeyer type operators, Appl. Math. Comput. 225 (2013), 195-203.

[8] V. Gupta, M. K. Gupta And V. Vasishtha, Simultaneous approximation by summation integral type operators, J. Nonlinear Funct. Anal. Appl. 8 (3) (2003), 399-412.

[9] V. Gupta And P. Maheshwari, Bézier variant of a new Durrmeyer type operators, Rivista di Matematica della "Università di Parma" 7 (2) (2003), 9-21.

[10] V. GUPTA AND R. YADAV, On approximation of certain integral operators, Acta Math. Vietnam. 39 (2014), 193-203.

[11] V. Gupta AND D. AgRawal, Approximation results by certain genuine operators of integral type, Kragujevac, Journal of Mathematics, 42 (3) (2018), 335-348.

[12] M. Heilmann And G. TACHEv, Commutativity, direct and strong converse results for Phillips operators, East J. Approx. 17 (3) (2011), 299-317.

[13] N. ISPIR AND I. YUKSEL, On the Bézier variant of Srivastava-Gupta operators, Appl. Math. E-Notes 5 (2005), 129-137.

[14] A. KaJla, A. M. ACU And P. N. AgRawal, Baskakov-Szász-type operators based on inverse PólyaEggenberger distribution, Annals of Functional Analysis 8 (1) (2017), 106-123.

[15] G. Mastroianni, Su una classe di operatori lineari e positivi, Rend. Acc. Sc. Fis. Mat., Napoli 48 (4) (1980), 217-235.

[16] V. MineşAn, Gamma approximating operators, Creat. Math. Inf. 17 (2008), 466-472. 
[17] A. J. Mohammad And A. K. Hassan, Simultaneous approximation by a new sequence of SzászBeta type operators, Rev. de la un. Mat. Argentina 50 (1) (2009), 31-40.

[18] R. S. PHILLIPS, An inversion formula for Laplace transformation and semi-groups of linear operators, Ann. Math. 59 (1954), 325-356.

[19] H. M. SRIVASTAVA AND V. GuPTA, A certain family of summation-integral type operators, Math. Comput. Model. 37 (2003), 1307-1315. 